\title{
Trends in urban/rural inequalities in physical growth among Chinese children over three decades of urbanization in Guangzhou: 1985-2015
}

Yan Hu ${ }^{1+}$, Weiqun Lin ${ }^{2+}$, Xuying Tan ${ }^{1}$, Yu Liư ${ }^{3}$, Yuqi Wen ${ }^{1}$, Yanfei Xing ${ }^{1}$, Ying Ma ${ }^{1}$, Huiyan Liu', Yanyan Song ${ }^{1}$, Jingjing Liang ${ }^{1}$, Kin Bong Hubert Lam ${ }^{4}$ and Suifang $\operatorname{Lin}^{1 *}$ (D)

\begin{abstract}
Background: Great growth inequalities between urban and rural areas have been reported in China over the past years. By examining urban/rural inequalities in physical growth among children $<7$ years old over the past three decades from 1985 to 2015 in Guangzhou, we analyzed altering trends of anthropometric data in children and their association with economic development during the period of rapid urbanization in Guangzhou.

Methods: The height, body weight and nutrition status of children under 7 years old were obtained from two successive cross-sectional surveys and one health surveillance system. Student's $t$-test, Spearman's rank-order correlation and polynomial regression were used to assess the difference in physical growth between children in urban and rural areas and the association between socioeconomic index and secular growth changes.
\end{abstract}

Results: A height and weight difference was found between urban and rural children aged 0-6 years during the first two decades of our research (1985-2005), which gradually narrowed in both sex groups over time. By the end of 2015, elder boys (age group $\geq 5$ year) and girls (age group $\geq 4$ year) in rural areas were taller than their counterparts in urban areas $(p<0.05)$.The same trend could be witnessed in the weight of children aged 6 years, with a $-1.30 \mathrm{~kg}$ difference $(P=0.03)$ for boys, and a -0.05 difference $(P=0.82)$ for girls. When GDP increased, the gap in boys' weight-for-age z-score (WAZ from 0.25 to 0.01 ) and height-for-age z-score (HAZ from 0.55 to 0.03 ) between urban and rural areas diminished, and disappeared when the GDP per capita (USD) approached 25,000. In either urban or rural areas, the urbanization rate and GDP were positively associated with the prevalence of obesity (all $R>0.90$ with $P<0.05$ ) and negatively correlated with the prevalence of stunted growth (all $R<-0.87$ with $P<0.05$ ).

Conclusion: Growth inequalities gradually decreased with economic development and urbanization, while new challenges such as obesity emerged. To eliminate health problems due to catch-up growth among rural children, comprehensive intervention programs for early child growth should be promoted in rural areas.

Keywords: Health inequalities, Physical growth trend, Economic reform, Guangzhou city

\footnotetext{
* Correspondence: suifanglin@163.com

${ }^{\dagger}$ Yan $\mathrm{Hu}$ and Weiqun Lin contributed equally to this work.

'Department of Children Healthcare, Guangzhou Women and Children's

Medical Center, Guangzhou Medical University, Guangzhou 510623, People's

Republic of China

Full list of author information is available at the end of the article
}

(c) The Author(s). 2020 Open Access This article is licensed under a Creative Commons Attribution 4.0 International License, which permits use, sharing, adaptation, distribution and reproduction in any medium or format, as long as you give appropriate credit to the original author(s) and the source, provide a link to the Creative Commons licence, and indicate if changes were made. The images or other third party material in this article are included in the article's Creative Commons licence, unless indicated otherwise in a credit line to the material. If material is not included in the article's Creative Commons licence and your intended use is not permitted by statutory regulation or exceeds the permitted use, you will need to obtain permission directly from the copyright holder. To view a copy of this licence, visit http://creativecommons.org/licenses/by/4.0/ The Creative Commons Public Domain Dedication waiver (http://creativecommons.org/publicdomain/zero/1.0/) applies to the data made available in this article, unless otherwise stated in a credit line to the data. 


\section{Background}

Height and weight are important indicators in measuring children's physical growth and development [1]. They not only reflect nutrition and health condition in children, which is related to their socioeconomic status, but also influence their well-being and quality of later life [2, 3]. Investigating the secular trend in physical growth for 0- to 7-year-old children reveals the patterns of child growth and thus, provides valuable biological evidence for policymakers to develop public health strategies [2].

Since the 1950s, several studies have compared the secular growth trends between girls and boys in China's urban and rural areas $[4,5]$. Over the past three decades, rapid economic development and enhanced living standards have enabled positive secular trends in children's physical growth. Anthropometric measurements have become crucial for assessing socioeconomic status [4]. However, the significant regional, east-west and socioeconomic disparities in China and their effect on children's physical growth cannot be ignored [6-8]. Under the economic reform in China, Guangzhou, as a pioneer of this economic opening, has been through rapid urbanization and economic development $[9,10]$. At the same time, income inequalities have emerged, along with an increase in health inequalities [11]. Limited studies have tried to link inequalities of children's growth to dramatic socioeconomic changes, which acts as important evidence for the government to develop policies that improve early childhood development and health care $[2,12]$. With the fast economic development in China, how inequalities in child growth development have changed over the past years in urban and rural areas of Guangzhou remains unclear, and further study is needed to estimate the magnitude of differences in urban and rural areas.

The present study investigated the influence of economic development in health inequalities. The goal of this study was to describe inequalities in child growth and its trend from 1985 to 2015 in Guangzhou. We focused on assessing 1) the difference in urban/rural child growth rate and its change over the past 30 years, 2) whether growth inequalities have disappeared under urbanization in Guangzhou, and 3) the association between economic development and growth inequality.

\section{Methods}

\section{Data sources}

Data used to estimate the growth and nutritional status of children aged $<7$ years were extracted from crosssectional surveys, including: National Survey on the Physical Growth and Development of Children in the Nine Cities in China (NSPGDC) [13], National
Epidemiology Survey on Simple Obesity in Childhood (NESSOC) [14], China National Maternal and Child Health Surveillance System (MCHSCN). A summary of these surveys were presented in Supp. Table 1. The study was approved by the Ethics Committees of Capital Institute of Pediatrics (SHERLL 2015009).

\section{Growth data}

Growth data were included from the second to the fifth NSPGDC $[15,16]$. The surveys were conducted in 1985 , 1995, 2005 and 2015 respectively. As a national research site, we collected children's physical growth data in Guangzhou.

We used a multi-staged, stratified cluster-sampling method following the NSPGDC guideline. First, we stratified subjects by urban (Yuexiu, Liwan and Haizhu Districts) and rural (Conghua, Huadu, Panyu and Baiyun Districts) areas based on the level of socioeconomic development. The partitioning of urban and rural areas was cited from a previous research which used a location quotient to reflect regional characteristics, including gross regional product per unit area, population density, non-agricultural population ratio and etc., of a specific area in Guangzhou [17].

Next, we sampled hospitals (for infants under 1 month of age), neighborhood communities (for children aged 1 month to 3 years) and kindergartens (for children aged 3 to 6 years) in corresponding areas as the cluster units. Participants with the following conditions were excluded: a) infants born before 37 weeks of gestation or weighed less than $2.5 \mathrm{~kg}$ at birth, b) twins or other multiple births, c) children with congenital, endocrine, neurological or chronic systemic diseases, d) children who have had a fever for more than 7 days within the past 2 weeks, e) continuous diarrhea more than 5 times/day for no less than 5 days.

Children were grouped by sex (male/female), age (at birth, 1 month, 2 months, 3 months, 4 months, 5 months, 6 months, 8 months, 10 months, 12 months, 15 months, 18 months, 21 months, 2 years, 2.5 years, 3 years, 3.5 years, 4 years, 4.5 years, 5 years, 5.5 years and 6-6.9 years) and region (urban/suburban). Consequently, we included a total of 67,545 children, and each sex/age subgroup of urban/suburban areas included 150-200 children (Supplementary Table 1).

Two well-trained investigators collected anthropometric data from each child. Height was measured without shoes and rounded to the nearest $0.1 \mathrm{~cm}$ (the length was measured for children aged < 3 years). Their weight was measured with light clothing and rounded to the nearest $0.05 \mathrm{~kg}$ following standard techniques described in previous research [15]. Each measurement was repeated three times with means rounded to the nearest $0.1 \mathrm{~cm}$. 


\section{Obesity and stunted growth data}

We obtained data on the prevalence of obesity from 1996 to 2015 in NESSOC. The NESSOC was conducted approximately every 10 years. All children aged $<7$ years who lived in administrative urban areas (Yuexiu and Haizhu Districts) or rural areas (Panyu and Huadu Districts) in 2006 were included in this study. The total sample size ranged from 6000 to 8000 (Supplementary Table 1). Data on the prevalence of stunted growth among children aged $<7$ years were obtained from the MCHSCN. We gathered data from nearly 800,000 children per year.

Obesity was defined using weight for height index for $0-2$-year-old children or body mass index for children older than 2 years. Children were categorized as obese if their corresponding indicators were $>3$ standard deviations (SD) from the mean level according to the standardized growth charts from the Working Group on Obesity in China [18]. Stunted growth was defined by length or height for age (LA or HA $<-2 \mathrm{z}$-score) based on the WHO Child Growth Standard (2006).

\section{Economic data}

Indicators of economic development (gross domestic product [GDP] per capita and urbanization rate) in Guangzhou were obtained from the Statistical Yearbook of the Guangzhou Statistics Bureau [19].

\section{Data analysis}

We calculated means and SDs for continuous variables and percentages for categorical variables. Absolute growth differences were calculated according to the following formula:

\section{Growth difference $=G_{\text {urban }}-G_{\text {rural }}$}

where $G_{\text {urban }}$ and $G_{\text {rural }}$ represent the mean height or weight for urban and rural children, respectively. To identify and compare temporal changes of growth patterns in urban and rural children, height/weight zscores adjusted for age and sex (HAZ/WAZ) were calculated using the Chinese national growth standards of 2005 [20] with the formula:

$$
z-\text { score }=\frac{x-\mu}{\sigma}
$$

where $x$ is the mean measurement for age, $\mu$ and $\sigma$ is the age- and sex-specific reference mean and standard deviation for $x$.

Degree of urbanization was calculated by the proportion of the non-agricultural population. Student's $t$-test were used to compared height and weight between rural and urban groups. Prevalence of obesity and stunted growth were assessed using a chi-square test. Spearman's rank-order correlation coefficients were used to analyze the correlation between GDP per capital and urbanization rate and the prevalence of obesity and stunted growth. $P$ value $<0.05$ was defined as statistically significant. Polynomial regression was used to analyze the trend correlation between GDP per capital and HAZ/WAZ. All data analyses were performed using $R$ software version 3.5.1 (https://www.r-project.org/).

\section{Results}

Urban/rural height and weight differences in Guangzhou Urban/rural differences in growth were calculated by the formula listed in the methods section, and further analyzed by the Student's $t$-test. As shown in Fig. 1 and Supplementary Fig. 1, urban children were significantly taller than their rural counterparts in most age groups during the first 2 decades (1985-2005). However, height differences between urban and rural children have gradually narrowed in both sex groups over time. By the end of 2015, elder boys and girls (boys aged 5, 5.5 and 6 years and girls aged 4, 4.5, 5, 5.5 and 6 years) in the rural area were taller than their counterparts in the urban areas $(P<0.05$, supplementary Table 2$)$. Interestingly, a fluctuating trend was observed in urban/rural weight difference as shown in Fig. 1c. The gap between areas became small during the first decade (1985-1995), but then it re-emerged between 1995 and 2005. Again, the gap narrowed in 2015. In 1985, the weight difference of 6-year-olds between urban and rural areas was $1.03 \mathrm{~kg}$ (95\%CI: $0.62,1.44, P=0.04$ ) for boys and $1.06 \mathrm{~kg}$ (95\%CI: $0.61,1.51, P=0.04$ ) for girls. However, by the year 2015, the weight of boys in rural areas exceeded that of urban areas in the same age group, with a -1.30 $\mathrm{kg}$ difference $(95 \% \mathrm{CI}:-2.04,-0.56, P=0.03$, supplementary Table 3), while the weight of the girls in rural and urban areas were basically the same (difference: $-0.05,95 \% \mathrm{CI}:-0.70,0.60, P=0.82$ ). These results showed a significant change in the physical growth inequalities between urban and rural children in Guangzhou.

\section{Inequalities in growth z-score and their association with economic development in Guangzhou}

To assess the inequalities of physical growth in urban and rural children across a diverse age group over the past 30 years, HAZ and WAZ in each sex group were computed and further analyzed by the student's $t$-test. HAZ and WAZ in different areas and their difference were showed in Fig. 2. Both HAZ and WAZ of urban children had been on a persistent upward trend between 1985 and 2005 but had been on a slight downward trend since 2005. For rural children, a continuous upward trend was observed in both height and weight since from 1985 to 2015. However, the gap in WAZ and HAZ between boys from urban and rural areas diminished 


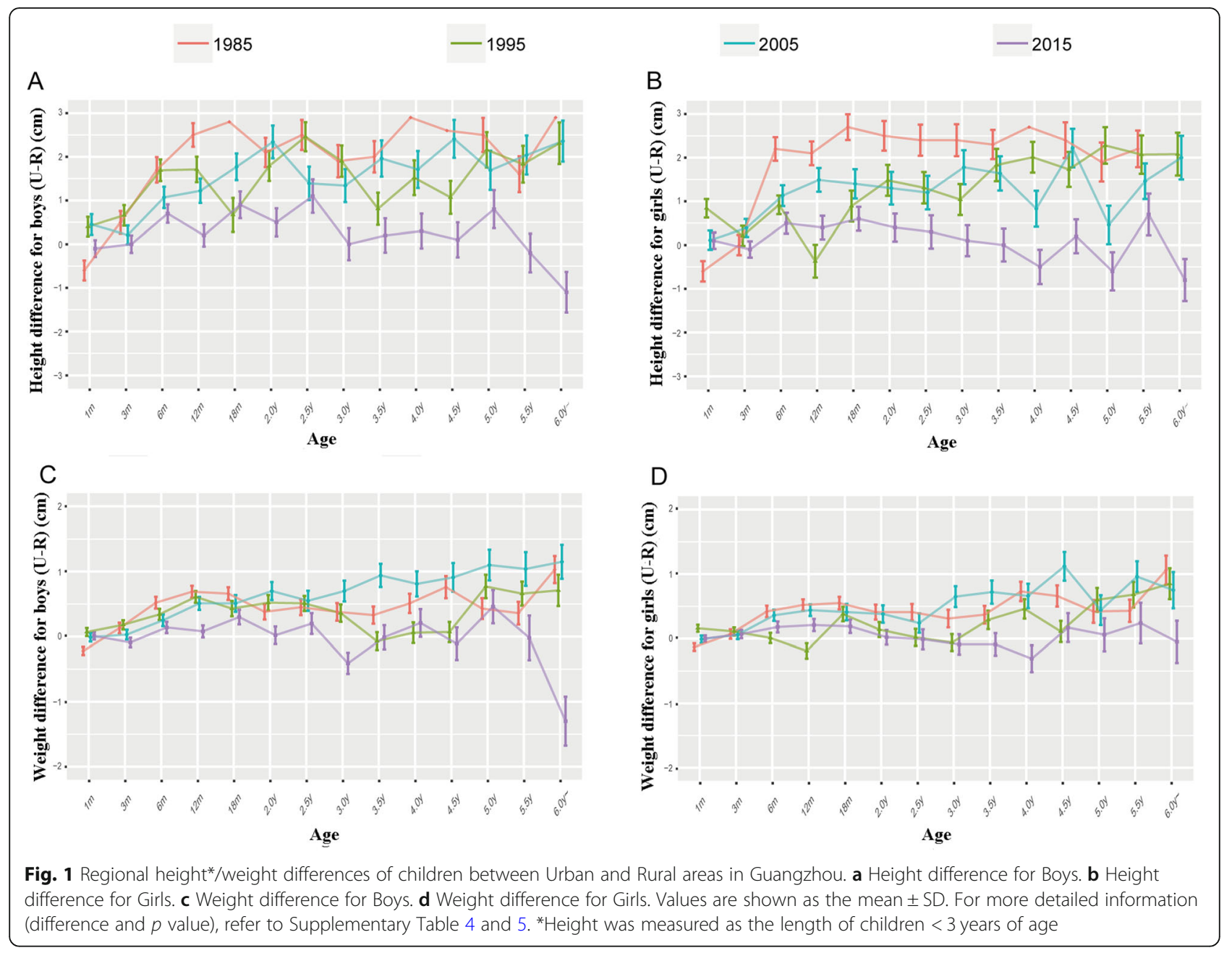

(from 0.25 to 0.01 and from 0.55 to 0.03 , respectively). The same change was also observed in girls, with the difference in WAZ from 0.25 to 0.04 and HAZ from 0.55 to 0.04 .

Furthermore, the association between economic development and z-scores were demonstrated in Fig. 3. With the development of GDP, the gap in boys' weight between urban and rural areas narrowed, and disappeared when the GDP approached 25,000. It is displayed that the association pattern between economic growth and physical growth is an inversely U-shaped curve. Such trends can also be seen in the height of boys and girls, and weight of girls in urban and rural areas. These results indicated a trend of regional inequality in children's physical growth, and these inequalities were associated with economic development.

\section{Trends in the prevalence of obesity and stunted growth in children in Guangzhou}

The NESSOC surveys from 1996 to 2016 showed an increasing prevalence of obesity: the prevalence of obesity increased 10.2-fold in urban children, from $0.54 \%$ in 1996 to 5.53\% in 2015, and 34-fold in rural children, from 0.23 to $7.82 \%$ (Supplementary Table 4). The prevalence of obesity in urban children increased rapidly during the three decades. In 2016, the prevalence of obesity in rural areas exceeded that in urban areas.

The prevalence of stunted growth in urban children was $2.18 \%$ in 1995 and decreased to $1.12 \%$ in 2015 (Supplementary Table 5). Among rural children, the prevalence was $2.96 \%$ in 1995 and decreased to $0.99 \%$ in 2015. The prevalence of stunted growth significantly decreased in both rural and urban area, with a greater reduction in rural areas (66.51\% vs $48.73 \%)$.

\section{The association between children growth status and socioeconomic development}

The association between socioeconomic development and child growth were demonstrated in Fig. 4 and Fig. 5. The urbanization rate increased from $45.5 \%$ in 1985 to $85.5 \%$ in 2015. Strong positive associations were found between the prevalence of obesity and urbanization rate 


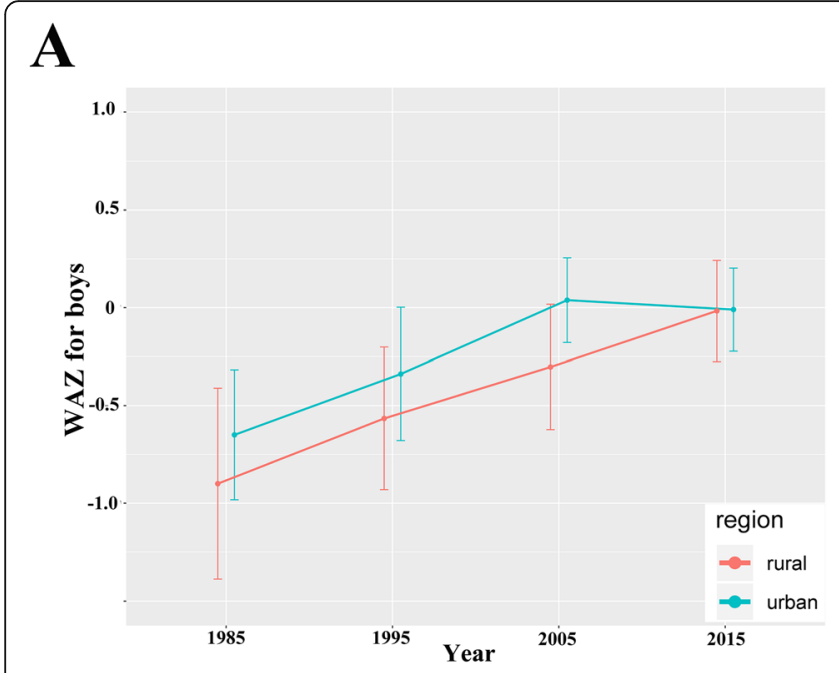

\section{B}

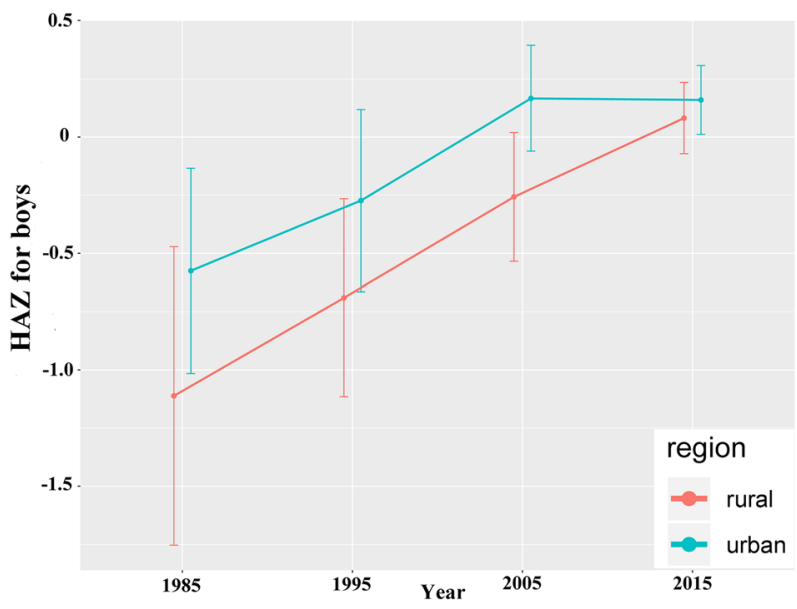

C

D
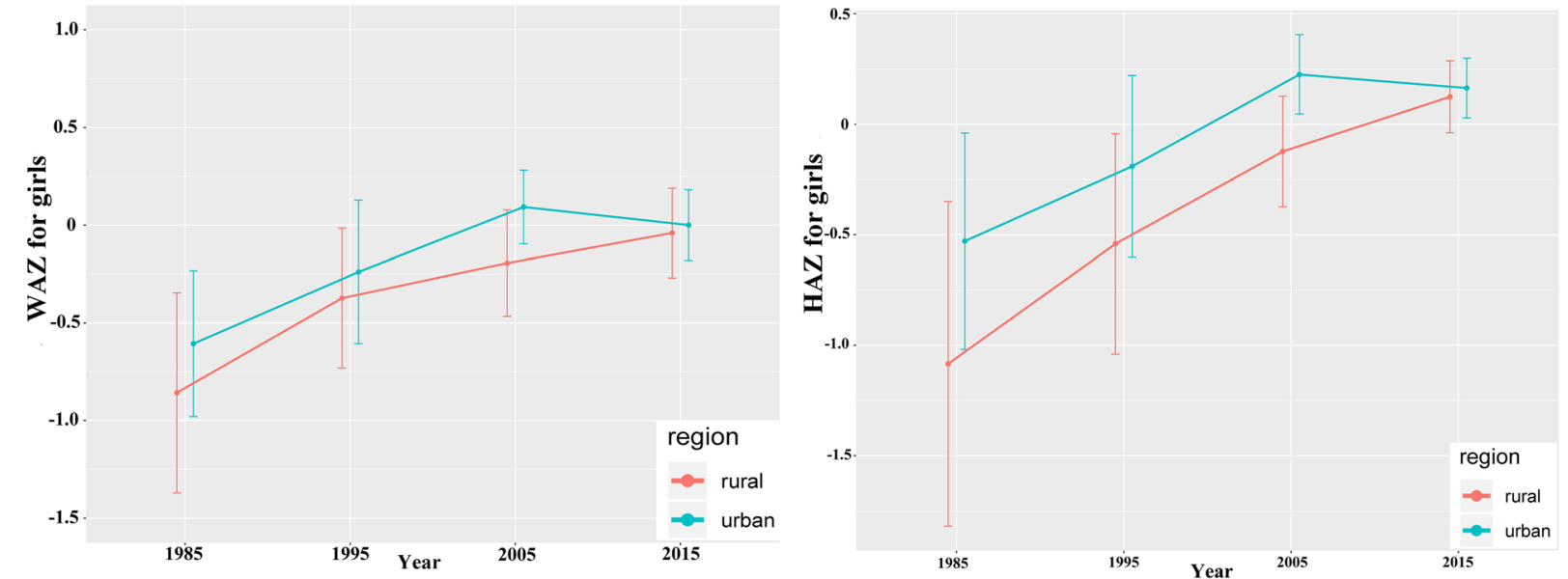

Fig. 2 HAZ and WAZ of children between Urban and Rural areas in Guangzhou, 1985-2015. a WAZ for boys. b HAZ for boys. c WAZ for girls. d HAZ for girls. Values are shown as the mean \pm SD

with estimated correlation coefficients $R=0.975(P=0.02)$ in urban children and $R=0.918(P=0.03)$ in rural children. And strong negative associations were also observed between the stunting prevalence and urbanization rate with $R=-0.899(P=0.03)$ in urban area and $R=-0.891(P=0.04)$ in rural area. Similar associations between changes in child nutritional status and GDP were detected, having the correlation coefficients $R=0.998(P=0.03)$ and $R=0.991 \quad(P=0.04)$ for the obesity prevalence in urban children, and $R=-0.975(P<0.01)$ and $R=-0.868(P=0.04)$ for the stunting prevalence in rural children.

\section{Discussion}

In this study, we illustrated the secular trend in the physical development of children in urban and rural areas during 1985-2015 in Guangzhou. Results showed that the difference in height and weight decreased significantly from 1985 to 2015. In 2015, older children in rural areas weighted heavier than those of urban areas on average. Meanwhile, obesity kept increasing significantly in both areas, which seemed to be a more severe problem in rural areas. The prevalence of stunted growth decreased in both rural and urban areas. Economic development and urbanization were strongly associated with the prevalence of obesity and stunted growth.

As one of the largest cities in China, Guangzhou has underwent rapid urbanization, great improvement in economy and public health in the past three decades $[21,22]$. GDP per capita in Guangzhou has increased from about 784 USD in 1985 to 21,835 USD in 2015. There has been a positive trend in the physical growth of Chinese children with socioeconomic progress [23]. 


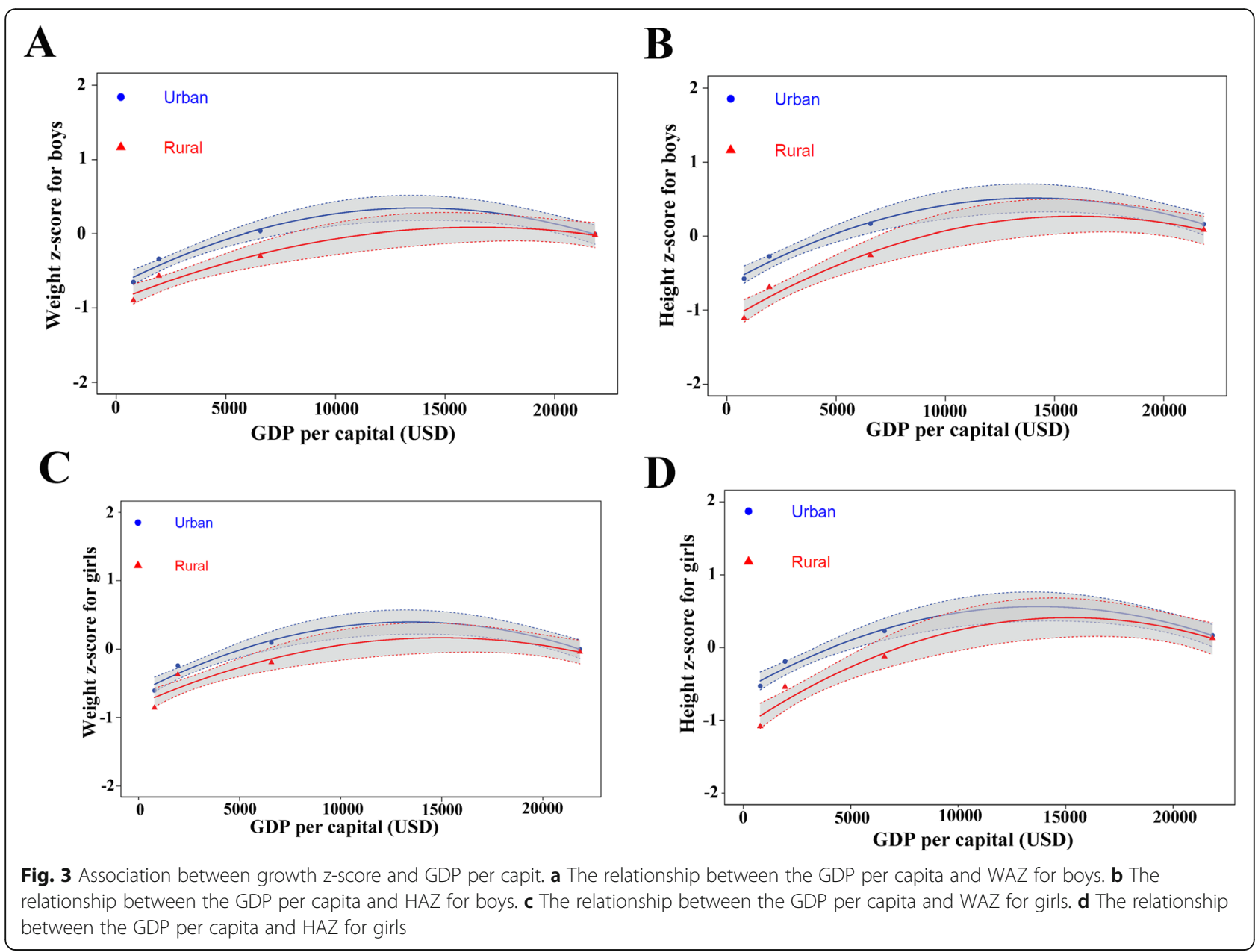

In our study, we found that the physical growth of children in Guangzhou had increased significantly, and the inequality in their growth between urban and rural areas decreased in the past three decades. These results were consistent with previous studies [24-26]. NSPGDC literature from national data, showed that between 1985 and 2005, those who lived in a coastal city such as Guangzhou was taller on average, than those living in inland and small-medium size cities [27]. In the early stage of the study (1985-1995), the marked growth inequalities might result from poor economic status, lack of insurance and limited access to health services [28, 29]. In the middle stage (1995-2005), substantial urban/ rural inequalities remained, in parallel with a sustained upward trend in physical growth. The decreasing health inequalities were probably due to the rapid economic development and the Basic Health Insurance Scheme policy in China [30, 31]. The gap between the physical growth of urban and rural children was further narrowed in the late stage (2005-2015). New health reforms, such as New Rural Co-operative Medical Care System (NRCMCS), were proposed during the same period. This basic public-health service project aimed to achieve health equity [32,33], especially for children of migrant workers who lived in the suburbs of Guangzhou $[34,35]$. In summary, economic development and expanding health care services largely decreased the urban/rural growth inequalities.

The differences in growth between urban and rural areas have narrowed over time. Generally, the physical growth status in children under 7 years old had been developed during the three decades both in rural and urban areas in Guangzhou. Besides, from the results of HAZ and WAZ in rural and urban areas and their differences in the three decades, we found that this gap of physical growth between rural and urban areas had become smaller since 2005. This changing pattern reflected that the physical growth rate of children in urban areas had decreased while increased in rural areas. These results were consistent with Xu's cross-sectional surveys during 1985-2010, which reported that urban/ rural differences in height were narrowed among children and adolescents aged 7-18 years in China [2]. In the Netherlands, the world's tallest population has come 

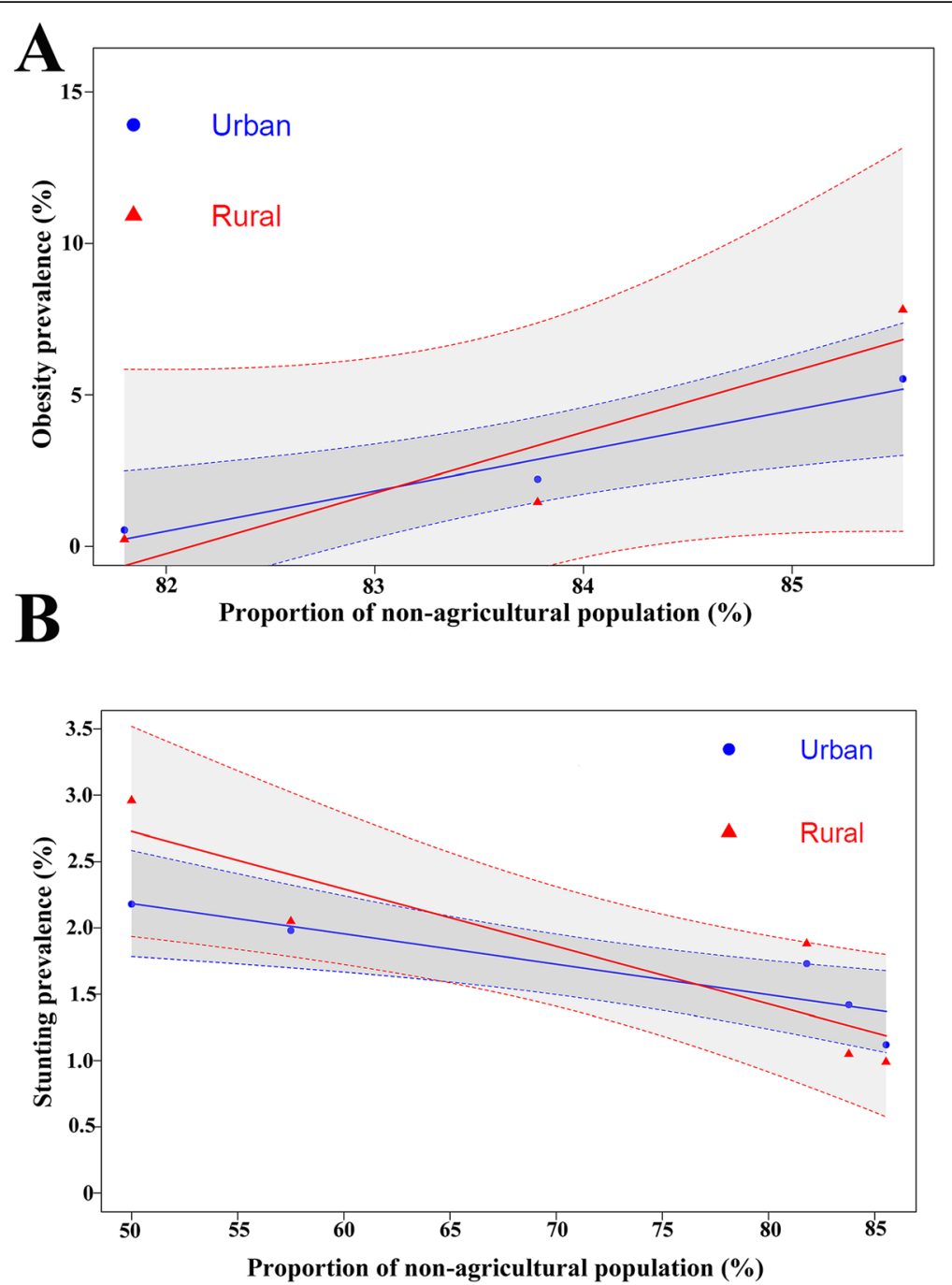

Fig. 4 Association between urbanization rate and child nutritional status in 2015. a The relationship between the proportion of non-agricultural population and the prevalence of obesity in urban and rural areas. $\mathbf{b}$ The relationship between the proportion of non-agricultural population and the prevalence of stunted growth in urban and rural areas

to a halt after 150 years of secular growth, which may have reached the optimal height distribution [36]. Generally, economy affects children's physical development by health care access, sanitary condition, nutrition and local infrastructure. Although income inequalities exist in urban and rural areas, adequate supply of nutrition, the improving economic and living conditions and better access to health care have gradually decreased the differences in growth rate of rural and urban children. Therefore, children in rural areas are catching up.

Another important nutritional issue was identified when physical growth of children was examined. The primary finding of our present study was that the prevalence of obesity in rural children increased 34-fold, which was more than that in urban children with better socioeconomic situations. Rapid urbanization in rural areas has led to new public health problems in children. It is widely reported that many changes in diet and physical activity are occurring simultaneously in the developing world and rural areas [37]. These changes were followed by a dramatic increase in obesity, hypertension and cardiovascular disease [38]. Urbanization and improving the economy in rural areas have enabled the rural population to purchase more processed foods and animal source foods [39, 40]. Also, only a few people in rural areas received high education, and instead most of them lacked the knowledge of maintaining a healthy life style and preventive strategies for chronic diseases [41-43]. A large proportion of the agricultural population and migrant population in the manufacturing industry lived in rural areas [44]. Therefore, there might be fewer effective behavioral interventions to prevent 

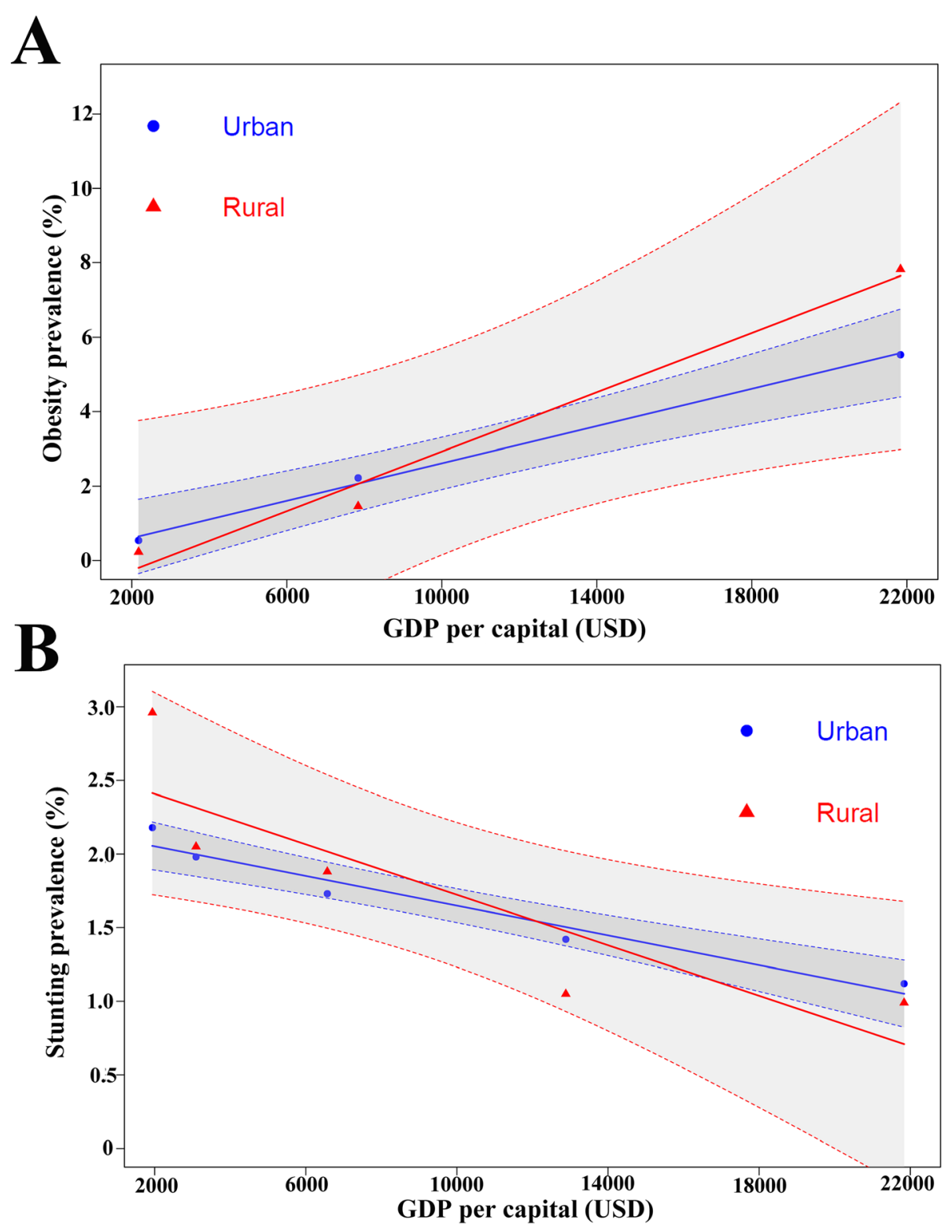

Fig. 5 Association between GDP per capita and child nutritional status in 2015. a The relationship between the GDP per capita and the prevalence of obesity in urban and rural areas. $\mathbf{b}$ The relationship between the GDP per capita and the prevalence of stunted growth in urban and rural areas

obesity [45].Our work highlighted an urgent need for developing appropriate interventions for children in the rural areas.

There were several strengths in our present study. Guangzhou represents an epitome of rapid urbanization and economic growth in China. Hence, it is important to examine the influence of its social changes over the past 30 years on child development. The results might predict the trends in other parts of China and even other developing countries that are going through dramatic social changes. In addition, the national surveillance data used in the present study was gathered throughout 30 successive years under strict quality control, and our study included a substantial proportion of the Chinese population in each period. However, several limitations existed in the present study. First, we lack the data of obesity and stunted growth from 1985 to 1995 . We were not able to analyze or evaluate developmental indicators in depth in this period. Second, due to the limited number of data nodes in our survey, we were cautious in inferring the association between GDP, urbanization and growth, which might not be applicable for each individual. Furthermore, since the detailed demographic data of NSPGDC from 1985 to 2005 were not collected, we 
could not adjust for potentially important determinants of growth such as family income and parental education level in the present study. Therefore, how these determinants influence and to what extent they can explain the weight and height inequalities between urban and rural children remained unclear.

\section{Conclusions}

In summary, our study showed great differences in the trend of physical growth between urban and rural children aged 0-6years in Guangzhou. Although the economic growth and urbanization promoted the physical growth of rural children, emerging problems such as obesity is becoming a new challenge. Therefore, more public health services should be offered to migrant children and other disadvantaged situations should be improved. To eliminate health problems caused by child catch-up growth in rural areas, comprehensive intervention programs for early-childhood development should be promoted in rural areas. In particular, standardized child health-care services should be given early in life at community health service centers.

\section{Supplementary information}

Supplementary information accompanies this paper at https://doi.org/10. 1186/s12889-020-09239-7.

Additional file 1: Figure S1. Changes in physical growth of children $<7$ years old in urban/rural areas in Guangzhou, 1985-2015. Table S1. Sample size of each subgroup in the NSPGDCs surveys, by sex-age. Table S2. Urban-rural height difference. Table S3. Urban-rural weight difference. Table S4. The prevalence of obesity in children $<7$ years old in urban/rural areas in Guangzhou, 1996-2016. Table S5. The prevalence of Stunted growth in children $<7$ years old in urban/rural areas in Guangzhou, 1995-2015.

\section{Abbreviations}

NSPGDC: National Survey on the Physical Growth and Development of Children in the Nine Cities in China; NESSOC: National Epidemiology Survey on Simple Obesity in Childhood; MCHSCN: China National Maternal and Child Health Surveillance System; HAZ: height-for-age; WAZ: weight-for-age; GDP: Gross Domestic Product

\section{Acknowledgments}

The authors thank all participants and researchers in carefully measuring and collecting the data.

\section{Authors' contributions}

$\mathrm{YH}, \mathrm{WL}, \mathrm{KBHL}$ and $\mathrm{SL}$ drafted the article; XT, YX, YM, HL and SL conducted research and collected the data; $Y L, Y S, J L$ and $Y W$ performed the statistical analysis. All authors read and approved the final manuscript.

\section{Funding}

The research was funded by a grant from the Science and Technology Plan of Guangdong Province (Grant 2017A020214002) and the project of the youth science foundation of Guangzhou Women and Children's Medical Center (Grant Pre-NSFC-2018-009). The views expressed herein do not necessarily reflect the Chinese Government. The funders did not play a role in study design, data collection and analysis, decision to publish or preparation of the manuscript.

\section{Availability of data and materials}

The data of growth and nutritional status used in the present study was extracted from the following 3 datasets: National Survey on the Physical Growth and Development of Children in the Nine Cities in China (NSPGDC), National Epidemiology Survey on Simple Obesity in Childhood (NESSOC), China National Maternal and Child Health Surveillance System (MCHSCN). We conducted data colloection of the above three suveys in Guangzhou. We were permitted by the national research group in China to analyse the data of our own collection and publish the results publicly. The economic data used in our present study were obtained from the Statistical Yearbook of the Guangzhou Statistics Bureau, which could be accessed in the official website (http://210.72.4.58/portal/querylnfo/statisticsYearbook/index).

\section{Ethics approval and consent to participate}

The study was approved by the Ethics Committees of Capital Institute of Pediatrics (SHERLL 2015009) and the informed consent was provided for ethical review. The written informed consent of each participant was obtained from a parent or guardian.

\section{Consent for publication}

Not applicable.

\section{Competing interests}

The authors declare that they have no competing interests.

\section{Author details}

'Department of Children Healthcare, Guangzhou Women and Children's Medical Center, Guangzhou Medical University, Guangzhou 510623, People's Republic of China. ${ }^{2}$ Department of Clinical Nutrition, The First Affiliated Hospital of Guangdong Pharmaceutical University, Guangzhou 510080, People's Republic of China. ${ }^{3}$ Department of Medical Statistics and Epidemiology, School of Public Health, Sun Yat-sen University, Guangzhou, China. ${ }^{4}$ Nuffield Department of Population Health, University of Oxford, Oxford, UK.

Received: 20 March 2020 Accepted: 12 July 2020

Published online: 31 July 2020

\section{References}

1. Zhang YQ, Li H, Zong H, Zhu Z, Pan Y, Li J, et al. The 5th national survey on the physical growth and development of children in the nine cities of China: anthropometric measurements of Chinese children under 7 year in 2015. Am J Phys Anthropol. 2017;163(3):497-509.

2. $\mathrm{Xu} \mathrm{Y,} \mathrm{Hang} \mathrm{L.} \mathrm{Height} \mathrm{inequalities} \mathrm{and} \mathrm{their} \mathrm{change} \mathrm{trends} \mathrm{in} \mathrm{China} \mathrm{during}$ 1985-2010: results from 6 cross-sectional surveys on children and adolescents aged 7-18 years. BMC Public Health. 2017;17(1):473.

3. Fogel RW, Engerman SL, Trussell J. Exploring the uses of data on height: the analysis of long-term trends in nutrition, labor welfare, and labor productivity. Soc Sci Hist. 1982;6(4):401-21.

4. Chen TJ, Ji CY. Secular change in stature of urban Chinese children and adolescents, 1985-2010. Biomed Environ Sci. 2013;26(1):13-22. https://doi. org/10.3967/0895-3988.2013.01.002.

5. Cardoso HF, Caninas M. Secular trends in social class differences of height, weight and BMl of boys from two schools in Lisbon, Portugal (1910-2000). Econ Hum Biol. 2010;8(1):111-20.

6. Du S, Lu B, Zhai F, Popkin BM. A new stage of the nutrition transition in China. Public Health Nutr. 2002;5(1A):169-74.

7. Cai J, Coyte PC, Zhao H. Decomposing the causes of socioeconomic-related health inequality among urban and rural populations in China: a new decomposition approach. Int J Equity Health. 2017;16(1):128.

8. Ge D, Chu J, Zhou C, Qian Y, Zhang L, Sun L. Rural-urban difference in the use of annual physical examination among seniors in Shandong, China: a cross-sectional study. Int J Equity Health. 2017;16(1):86.

9. Li J, Huang L, Yan LJ. Sustainable development of the three economic patterns in China: The application of genuine progress indicator in the sustainability assessment of six typical cities. Ying Yong Sheng Tai Xue Bao. 2016;27(6):1785-94. https://doi.org/10.13287/j.1001-9332.201606.021.

10. Zhou C, Sylvia S, Zhang L, Luo R, Yi H, Liu C, et al. China's left-behind children: impact of parental migration on health, nutrition, and educational outcomes. Health Aff (Millwood). 2015;34(11):1964-71. 
11. Chen L, Wu Y, Coyte PC. Income-related children's health inequality and health achievement in China. Int J Equity Health. 2014;13:102. https://doi. org/10.1186/s12939-014-0102-6

12. Li $X$, Sun $Y$, Zhang $X$, Wang J. Reductions in gut microbiotaderived metabolite trimethylamine Noxide in the circulation may ameliorate myocardial infarctioninduced heart failure in rats, possibly by inhibiting interleukin 8 secretion. Mol Med Rep. 2019;20(1):779-86. https://doi.org/10. 3892/mmr.2019.10297.

13. Zong XN, Li H, Zhu ZH. Secular trends in height and weight for healthy Han children aged 0-7 years in China, 1975-2005. Am J Hum Biol. 2011;23(2): 209-15.

14. Zong XN, Li H. Secular trends in prevalence and risk factors of obesity in infants and preschool children in 9 Chinese cities, 1986-2006. PLoS One. 2012;7(10):e46942.

15. Zhang YQ, Li H, Wu HH, Zong XN, Zhu ZH, Pan Y, et al. The 5th national survey on the physical growth and development of children in the nine cities of China: anthropometric measurements of Chinese children under 7 years in 2015. Am J Phys Anthropol. 2017;163(3):497-509.

16. Li X, Zhu J, Dai L, Li Q, Li W, Zeng W, et al. Hospitalized delivery and maternal deaths from obstetric hemorrhage in China from 1996 to 2006 Acta Obstet Gynecol Scand. 2011;90(6):586.

17. Qi X-h, Cheng Y, Chen L. Division of regional spatial structure in metropolitan area: a case study of Guangzhou. Trop Geogr. 2008;28(1):37-41.

18. Li H, Ji CY, Zong XN, Zhang YQ. Body mass index growth curves for Chinese children and adolescents aged 0 to 18 years. Zhonghua er ke za zhi. 2009; 47(7):493. 19951508.

19. Bureau GS. Guangzhou Statistical Yearbook [Available from: http://210 72.4.52/gzStat1/chaxun/njsj.jsp.2018.12.

20. Pediatrics Clo. Growth standardized values and curves based on weight for length/height, body mass index for Chinese children under 7 years of age. Zhonghua Er Ke Za Zhi. 2009;47(3):173-8 PMID: 19555567.

21. Zhu YG, loannidis JP, Li H, Jones KC, Martin FL. Understanding and harnessing the health effects of rapid urbanization in China. Environ Sci Technol. 2011:45(12):5099-104.

22. Li M, Wu YF. Urbanization and Public Health in China; 2016. p. 2-4.

23. Ji CY, Chen TJ. Secular changes in stature and body mass index for Chinese youth in sixteen major cities, 1950s-2005. J Am J Human Biol. 2008;20(5): 530-7.

24. Zhen-Wang B, Cheng-Ye J. Secular growth changes in body height and weight in children and adolescents in Shandong, China between 1939 and 2000. Ann Hum Biol. 2005;32(5):650-65.

25. Height B. A survey on the physical growth of children under 7 years in the urban and suburban rural areas of nine cities of China in 1995. Coordinating Group of Nine Cities on Physical Growth and Development of Children. Zhonghua Yi Xue Za Zhi. 1998;78(3):187 PMID: 10923526.

26. Ching RJ, Chen JQ, Han HT, Ma LH, Gu YF, Cui KX, et al. Physical growth of Chinese children from birth to 6 years old in urban and rural areas in 1985 J Trop Pediatr. 1989;35(5):255-60.

27. Zong XN, Li H. Physical growth of children and adolescents in China over the past 35 years. Bull World Health Organ. 2014;92(8):555-64.

28. Zhang $X$, Zhang $Y, X u$ J. Effect of lifestyle on sub-health situation of urban residents in Guangzhou. China J Health Psychol. 2014;6:78-80.

29. Chaolin L. Cook. Progress in research on Chinese urbanization. Front Architectural Research. 2012;1(2):101-49.

30. Hindle D. China in transition: the new health insurance scheme for the urban employed. Australian Health Review A Publication of the Australian Hospital Association. 2000;23(3):122. https://doi.org/10.1071/ah000122a.

31. Xu L, Wang Y, Collins CD, Tang S. Urban health insurance reform and coverage in China using data from National Health Services Surveys in 1998 and 2003. BMC Health Serv Res. 2007;7(1):37.

32. Meng Q, Tang S. Universal health care coverage in China: challenges and opportunities. Procedia - Social and Behavioral Sciences. 2013;77(77):330-40.

33. Qin JM. Progress in basic public health service projects in China. Chin J Public Health. 2017:33(9):1289-97.

34. Song $Y$, Xie Z. Impact of urban public resources on migration decision of rural children in China. Popul Res. 2017;41(5):52-62

35. Yip WC, Hsiao WC, Chen W, Hu S, Ma J, Maynard A. Early appraisal of China's huge and complex health-care reforms. Lancet. 2012;379(9818):833-42.

36. Schonbeck Y, Talma H, van Dommelen P, Bakker B, Buitendijk SE, HiraSing RA, et al. The world's tallest nation has stopped growing taller: the height of Dutch children from 1955 to 2009. Pediatr Res. 2013;73(3):371-7.
37. Ren M, Brauw AD. Migration and young child nutrition: evidence from rural China. J Popul Econ. 2015;28(3):631-57.

38. Popkin BM, Du S. Dynamics of the nutrition transition toward the animal foods sector in China and its implications: a worried perspective. J Nutr. 2003;133(11 Suppl 2):3898S.

39. Popkin BM. Will China's nutrition overwhelm its health care system and sloe economic growth? Health Aff. 2008;27(4):1064

40. Du S, Mroz TA, Zhai F, Popkin BM. Rapid income growth adversely affects diet quality in China_particularly for the poor! Soc Sci Med. 2004;59(7): 1505-15.

41. Chen JW, Xin-Hong XU, Luo MH, Luo LF, Zi-Jian HE. Study on the status of health literacy and its influencing factors among urban and rural residents in Guangzhou City. Chinese J Health Educ. 2016;32(7):601-05.

42. Li X, Song J, Lin T, Dixon J, Zhang G, Ye H. Urbanization and health in China, thinking at the national, local and individual levels. Environ Health. 2016;15(S1):S32.

43. $\mathrm{Xu} \mathrm{H}, \mathrm{Yu}$ X. Socioeconomic inequalities in health in China: a reassessment with data from the 2010-2012 China family panel studies. Soc Indic Res. 2017;132(1):1-21.

44. Xinhua Q, Yu C, Lie C. Research on regional spatial structure division of big cities-a case study of Guangzhou. Trop Geogr. 2008;28(1):37-41.

45. Van de Poel E, O'Donnell O, Van Doorslaer E. Urbanization and the spread of diseases of affluence in China. Econ Hum Biol. 2009;7(2):200-16. https:// doi.org/10.1016/j.ehb.2009.05.004.

\section{Publisher's Note}

Springer Nature remains neutral with regard to jurisdictional claims in published maps and institutional affiliations.

Ready to submit your research? Choose BMC and benefit from

- fast, convenient online submission

- thorough peer review by experienced researchers in your field

- rapid publication on acceptance

- support for research data, including large and complex data types

- gold Open Access which fosters wider collaboration and increased citations

- maximum visibility for your research: over $100 \mathrm{M}$ website views per year

At $\mathrm{BMC}$, research is always in progress.

Learn more biomedcentral.com/submissions 